\title{
Anaesthesia for Transoral Endoscopic Thyroidectomy
}

\author{
Charaka Yapa Abeywardana ${ }^{*}$, Ramya Amarasena ${ }^{2}$ \\ Registrar in Anaesthesiology ${ }^{1}$, Consultant Anaesthetist ${ }^{2}$, National Hospital of Sri Lanka, \\ Colombo, Sri Lanka
}

\begin{abstract}
The expanding realm of minimally invasive surgery incorporate specific anaesthetic challenges. This report transcribes the anaesthetic technique for the first successful Transoral Endoscopic Thyroidectomy (TOET) performed in Sri Lanka using 3-dimensional (3D) endoscopy at National Hospital of Sri Lanka.
\end{abstract}

Keywords: Transoral Endoscopic Thyroidectomy; nasal intubation; hypercarbia

\section{Introduction}

Minimally invasive TOET has been in development since Gagner's endoscopic subtotal parathyroidectomy in $1996^{1}$. Advantages of this method include elimination of a surgical neck scar, less bleeding, reduced analgesic requirement and a faster recovery. The following excerpt emphasises the anaesthetic challenges innate to TOET.

\section{Case report}

A 43yr old gentleman (weight $80 \mathrm{~kg}$, BMI $29 \mathrm{~kg} / \mathrm{m}^{2}$ ) presented with a progressive swelling of the lower half of neck for 18 months. No obstructive symptoms were present. Features of coexisting medical illnesses or obstructive sleep apnoea were absent. He was clinically and biochemically euthyroid. Neck ultrasonography revealed a $3.5 \times 2.6 \mathrm{cmnodule}$ originating from left thyroid lobe and isthmus.

Patient appeared apprehensive and was premedicated with diazepam. Mouth was gargled with betadine just prior to induction. Monitoring was established according to AAGBI standards. A $17 \mathrm{G}$ intravenous cannula was inserted to the dorsum of the left hand connected to a running drip with a $100 \mathrm{~cm}$ extension line primed with warmed Ringer lactate solution. IV coamoxyclav and metronidazole was given $30 \mathrm{mins}$ before procedure. Anaesthetic workstation was

*Correspondence: Charaka Yapa Abeywardana Email: charaka3@yahoo.co.uk

http://www.orcid.org/0000-0002-1708-4509 Received: 24/05/2018

Accepted:03/07/2018

DOI: http://doi.org/10.4038/slja.v26i2.8342 placed to the left. Patient was positioned as for a standard thyroidectomy.

Preoxygenation was done for 3 mins with $\mathrm{O}_{2}$ at $6 \mathrm{~L} / \mathrm{min}$ via circle circuit. Glycopyrrolate $20 \mathrm{mcg} / \mathrm{kg}$ was given i.v. as an anti-sialagogue. Induction was performed with fentanyl $2 \mathrm{mcg} / \mathrm{kg}$, propofol $2 \mathrm{mg} / \mathrm{kg}$ i.v, titrated to effect followed by atracurium $0.5 \mathrm{mg} / \mathrm{kg}$ i.v. A $7.5 \mathrm{~mm}$ cuffed reinforced nasal endotracheal tube (ETT) was inserted. Correct ETT placement was confirmed by waveform capnography and auscultation. A moist throat pack was placed. The eyes were taped shut and covered with a gauze. Head was fully extended and stabilized on a head ring with a sandbag placed underneath the shoulders. Morphine $0.1 \mathrm{mg} / \mathrm{kg}$ was given i.v. for analgesia.

Anaesthesia was maintained with $\mathrm{O}_{2}$ : air: isoflurane at $1 \mathrm{~L} / \mathrm{min}: 1 \mathrm{~L} / \mathrm{min}: 1-1.4 \%$. The minimum alveolar concentration was maintained at 1 . Lung protective ventilatory strategy was employed with tidal volumes of $7 \mathrm{ml} / \mathrm{kg}$, respiratory rate of $12 / \mathrm{min}$ and a positive endexpiratory pressure of $5 \mathrm{cmH}_{2} \mathrm{O}$. Peak airway pressure $\left(\mathrm{P}_{\mathrm{aw}}\right)$ stood around $22 \mathrm{cmH}_{2} \mathrm{O}$. End tidal $\mathrm{CO}_{2}\left(\mathrm{ETCO}_{2}\right)$ at the beginning of the surgery stood between $35-40 \mathrm{mmHg}$.

The surgeon occupied the head-end throughout the surgery. The inferior gingiva labial sulcus was washed with betadine followed by infiltration of $5 \mathrm{ml}$ of $2 \%$ lignocaine with adrenaline (1:200000). 3 port entry was made with one midline and two paramedian ports with care taken to avoid injury to mental nerve during placement. $\mathrm{CO}_{2}$ was insufflated slowly into the subplatysmal plane to a working pressure of $6 \mathrm{mmHg}$. 3D endoscopy with magnified vision helped in fine dissection and preservation of important structures such as recurrent laryngeal nerve and parathyroid gland. 
$\mathrm{P}_{\mathrm{aw}}, \mathrm{ETCO}_{2}$ and endoscopic working pressure were monitored continuously. $\mathrm{ETCO}_{2}$ rose gradually as the surgery progressed. Minute ventilation was adjusted to keep $\mathrm{ETCO}_{2}$ between $30-40 \mathrm{mmHg}$ by increasing the respiratory rate up to $16 / \mathrm{min}$. Tidal volume remained the same. Normothermia was maintained with warmed intravenous fluids and body warmers. Left hemithyroidectomy and isthmectomy was performed. The pneumatic subplatysmal space was decompressed after ensuring complete haemostasis. Tight dressing was applied to compress the operative field. Total surgical time was 270 mins. Blood loss was approximately $60 \mathrm{ml} . \mathrm{ETCO}_{2}$ was allowed to normalize before recovery from anaesthesia commenced. Oropharynx was visualized directly with laryngoscope and secretions sucked out thoroughly. Throat pack was removed. Mild facial puffiness was noted at the end which subsided few hours later. There was no airway oedema.

The patient was reversed from neuromuscular block with neostigmine $0.04 \mathrm{mg} / \mathrm{kg}$ and atropine $0.02 \mathrm{mg} / \mathrm{kg}$ i.v. He spoke immediately after extubation and was pain free.

Oral fluids were started immediately after surgery and feeding resumed the following day. No residual voice change or surgical emphysema were present. Pain was minimal and was managed with regular oral paracetamol and diclofenac suppositories. Narcotic analgesics were never used for postoperative analgesia. After an uneventful stay, patient was discharged home on the second postoperative day.

\section{Discussion}

Endoscopic access to the thyroid gland is a matter of surgical preference. Transoral vestibular route was used for this patient.

A reinforced nasal tube was inserted to obviate the possibility of ETT disconnection during surgery with a throat pack inserted to prevent aspiration. Eyes were padded to avert inadvertent injury.

Literature suggest insufflation of $\mathrm{CO}_{2}$ at 10$12 \mathrm{mmHg}$ for working space creation and 6$8 \mathrm{mmHg}$ for working space maintenance. ${ }^{2,3}$ Contrary to conventional laparoscopy; where the systemic absorption of $\mathrm{CO}_{2}$ plateaus after first 20 minutes; extraperioneal $\mathrm{CO}_{2}$ absorption continue to increase over time. Mechanisms include higher

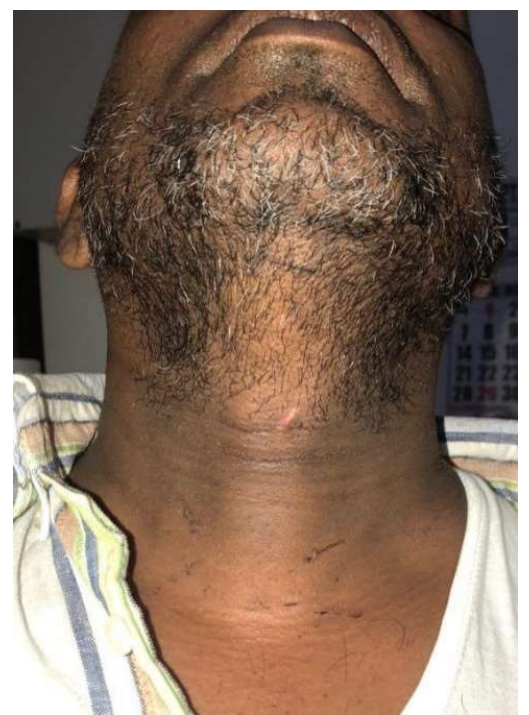

Figure 1. Post-operative appearance of TOET

initial insufflation pressuresand continued tissue dissection increasing absorptive surface area. ${ }^{3,4}$ Complications include $\mathrm{CO}_{2}$ gas embolisation, subcutaneous emphysema, pneumothorax, sympathetic hyperactivity, severe hypercarbia and acidosis. ${ }^{3}$ Accidental disconnection or kinking of airway tubing can happen due to airway sharing with surgeon which is compounded by complex equipment used over face. Constant vigilance on vital parameters, ETCO $_{2}$ and $\mathrm{P}_{\mathrm{aw}}$ should be made during TOET and minute ventilation adjusted guided by $\mathrm{ETCO}_{2}$ trends.

An important concern of TOET is the transmigration of oral cavity flora into subplatysmal space. Therefore, appropriate prophylactic antibiotics need to be administered preoperatively and continued into the postoperative period. Extubation and immediate post-surgical period was uneventful. Postoperative pain was minimal and was managed with mild analgesics as narcotic medication was not required. Patient had an accelerated recovery after TOET.

\section{Conclusion}

TOET post unique challenges to the anaesthetist in terms of airway protection without hindering surgical access whilst monitoring for local, respiratory and haemodynamic sequelae of $\mathrm{CO}_{2}$ insufflation. Improved surgical techniques for TOET will result in less tissue trauma with reduced operative times and less systemic $\mathrm{CO}_{2}$ absorption. Adherence to correct techniques and 
vigilant monitoring to avert anaesthetic complications culminated in a successful outcome with this novel procedure.

\section{Consent}

Direct consent was obtained from the patient for this publication.

\section{Declaration of interest}

None.

\section{References}

1. Gagner M. Endoscopic subtotal parathyroidectomy in patients with primary hyperparathyroidism. Br J Surg. 1996;83(6):875. https://doi.org/10.1002/bjs. 1800830656

PMid:8696772

2. Bhargav PRK, Kusumanjali A, Nagaraju R et al. What is the Ideal $\mathrm{CO} 2$ Insufflation Pressure for Endoscopic Thyroidectomy? Personal Experience with Five Cases of Goiter. World J

Endocr Surg. 2011;3:3-6.

https://doi.org/10.5005/jp-journals-10002-1045

3. Lee SN, Lee JH, Lee EJ. Anesthetic course and complications that were encountered during endoscopic thyroidectomy -A case report-. Korean J Anesthesiol. 2012;63(4):363.

https://doi.org/10.4097/kjae.2012.63.4.363

PMid:23115692 PMCid:PMC3483498

4. Anuwong A, Kim HY, Dionigi G. Transoral endoscopic thyroidectomy using vestibular approach: updates and evidences. Gland Surg. 2017;6(3):277-84.

https://doi.org/10.21037/gs.2017.03.16

PMid:28713700 PMCid:PMC5503927 